\title{
MANDIBULAR FRACTURES ASSOCIATED WITH DOMESTIC VIO- LENCE IN CALABAR, NIGERIA
}

\author{
C. E. ANYANECHI \\ Maxillofacial Unit, Department of Surgery, University of Calabar Teaching Hospital, \\ Calabar, Cross River State, Nigeria
}

Correspondence Author: Dr C. E. Anyanechi

Conflict of Interest: None declared

\section{SUMMARY}

Background: The purpose of this study was to analyze the pattern of mandibular fractures associated with domestic violence.

Methods: This prospective study was carried out at the University of Calabar Teaching Hospital (UCTH) in the Accident and Emergency Centre and Dental and Maxillofacial Clinic between the calendar years of 2005 and 2008 (four years). Only consecutive Dental and Maxillofacial injury cases that sustained mandibular fracture by domestic violence were included in the data collection.

Results: The ages of patients ranged from 15-42 years with a mean of $30 \pm 3.2$ years. Majority of the patients were in the second, third and fourth decades of life. There were 52(71.2\%) males and $21(28.8 \%)$ females with a male- to- female ratio of $2.5: 1$. There was significant association between social class and type of fracture sustained $(\chi 2=14.0, p=0.0073)$. Patients in the lower social class were more likely to sustain multiple fractures. The mechanisms of injury were by punching with the fist $41(56.2 \%)$, use of weapons $27(37.0 \%)$ and kicking with legs $5(6.8 \%)$. Majority of the fractures occurred at the angle, 52(31.3\%) and condyles, $45(27.1 \%)$. All the patients were treated by closed reduction technique. The complications recorded were delayed union, 5(38.4\%), infection, $3(23.1 \%)$, paraesthesia / anaesthesia of the lower lip, $3(23.1 \%)$ and malunion, 2(15.4\%).

Conclusion: Mandibular fractures due to domestic violence do occur and constitute part of the cases to be encountered by the practising oral and maxillofacial surgeon who should be cognizant to its surgical and social implication.

\section{INTRODUCTION}

The mandible is the most prominent bone in the face, suspended on two hinge joints on both sides of the skull. The incidence of occurrence of mandibular fractures is always on the increase because of the fast pace of life, increased violence and advent of rapid modes of transportation. Fractures of the mandible are therefore relatively common injuries caused by trauma. ${ }^{1,2}$
E-mail: ceanyanechi@yahoo.com

The occurrence of facial injuries tends to be high compared to injuries in other body areas because the face is without protective covering. ${ }^{2,3}$ The abruptness of the injury can cause intense emotional distress and the perception of the injury by the patient or relatives and their reaction may sometimes be out of proportion to the degree of injury.

Thus the clinician must be able to deal with the patients' physical injuries and emotional state. Domestic violence afflicts millions of people each year worldwide. $^{3}$ It is the most common cause of nonfatal injury in women. ${ }^{4}$ Apart from the awareness that most injuries resulting from domestic violence involve the facial region, there is little information about the pattern of this injuries to the mandible.

However, mandibular fractures are not usually a threat to life but occasionally death can result from asphyxia due to inhalation of blood from oral bleeding especially when combined with unconsciousness. ${ }^{2}$ These injuries sustained are sometimes overlooked by the physicians they initially present to during clinical assessment resulting subsequently in delayed appropriate treatment. ${ }^{3}$

This article analyzes the pattern of mandibular fractures that are commonly diagnosed in such patients and reveals the need to incorporate the oral and maxillofacial surgeons among the clinicians managing patients involved in domestic violence.

\section{PATIENTS AND METHODS}

This prospective study was carried out at the Accident and Emergency Centre and the Dental and Maxillofacial Clinic of the University of Calabar Teaching Hospital (UCTH), Calabar within the calendar years of 2005 to 2008 (four years). Calabar is a metropolitan city located in the South-South region of Nigeria.

Domestic violence in this study is defined as the use of physical force with or without weapon to cause body harm within the family or household. Only patients' who sustained injuries to the mandible by domestic violence were included in the study. 
Cases of gunshot injuries were excluded from the study. Detailed information on the aims of study was given to the patients, parents or guardians, as the case maybe.

Written informed consent for participation in the study was obtained from patients or guardian where applicable. Institutional consent was obtained from the Ethics Committee of the hospital. Records of patients' ages, gender, marital status and social class, mechanisms of injury, type, site, and number of fractures; treatment and complications were documented. Patients' socioeconomic status was classified using the Adedeji,s classification of $1985 .{ }^{5}$

The data obtained were analyzed using EPI Info 2000 version software. Descriptive statistics were obtained for all variables. Chi square values and values of levels of significance were obtained where appropriate. $\mathrm{P}$ values $<0.05$ were considered significant.

The study was subject to the following limitations: a). The duration of the study was not long enough to recognize delayed complications which may arise, after the study ended. b). Method of treatment with use of mini-plates and micro-plates which could have given better outcome was affected by non-accessibility and financial constraints on the part of the patients. c). Patients without complications, after successful treatment, were lost to follow-up.

\section{RESULTS}

Table 1 show the fracture distribution by age and gender. No patient was recorded in the first decade of life. Majority of the patients were in the second, third and fourth decades. The age of patients ranged from 15- 42 years with a mean of $30 \pm 3.2$ years.

Table 1 Fracture distribution by age and gender

\begin{tabular}{|l|c|c|c|r|}
\hline $\begin{array}{l}\text { Age } \\
\text { (years) }\end{array}$ & Males & Females & No. & \% \\
\hline $11-20$ & 16 & 7 & 23 & 31.5 \\
\hline $21-30$ & 23 & 5 & 28 & 38.4 \\
\hline $31-40$ & 11 & 9 & 20 & 27.4 \\
\hline $41-50$ & 2 & 0 & 2 & 2.7 \\
\hline Total & 52 & 21 & 73 & 100.0 \\
\hline
\end{tabular}

There were $52(71.2 \%)$ males and $21(28.8 \%)$ females with a male- to-female ratio of 2.5:1. Thirty-four $(46.6 \%)$ were single, 24(32.9\%) married and $15(20.5 \%)$ either separated or divorced.

Table 2 shows the distribution of fracture type by social class. There was significant association between social class and type of fracture sustained $(\chi 2=14.0$, $\mathrm{p}=0.0073$ ). There was significant association between social class and type of fracture sustained.

Table 2 Fracture distribution by social class

\begin{tabular}{|l|c|c|c|}
\hline $\begin{array}{l}\text { Social } \\
\text { Class }\end{array}$ & $\begin{array}{c}\text { Single } \\
\text { fracture } \\
\mathbf{n}(\%)\end{array}$ & $\begin{array}{c}\text { Multiple } \\
\text { fracture } \\
\mathbf{n}(\%)\end{array}$ & $\begin{array}{c}\text { Total } \\
\mathbf{n}(\%)\end{array}$ \\
\hline I & $4(66.7)$ & $2(33.3)$ & $6(100.00)$ \\
\hline II & $3(60.0)$ & $2(40.0)$ & $5(100.00)$ \\
\hline III & $4(19.0)$ & $17(81.0)$ & $21(100.00)$ \\
\hline IV & $2(8.7)$ & $21(91.3)$ & $23(100.00)$ \\
\hline V & $3(16.7)$ & $15(83.3)$ & $18(100.00)$ \\
\hline Total & $16(21.9)$ & $57(78.1)$ & $73(100.00)$ \\
\hline
\end{tabular}

Patients in the lower social class were more likely to sustain multiple fractures. On the mechanisms of injury, $41(56.2 \%)$ sustained their injury by punching with the fist while the use of weapons and kicking with legs accounted for $27(37.0 \%)$ and $5(6.8 \%)$ respectively. Thirty-three $33(45.2 \%)$ of the patients sustained simple fractures while compound fractures accounted for $40(54.8 \%)$. On the multiplicity of fracture, the 73 patients sustained 166 fractures. This approximates to 2.3 fractures per patient. Sixteen (21.9\%) patients sustained one fracture, $27(37.5 \%)$ patients' two fractures and $20(27.4 \%)$ patients' three fractures while nine $(5.5 \%)$ patients had four fractures.

The common fracture combinations observed were in descending order: body of the mandible and subcondylar on the contralateral side (20.2\%); ipsilateral angle, contralateral body and parasymphysis (14.6\%); symphysis, bilateral subcondylar and body $(3.8 \%)$. The fractures sustained with the use of weapons were more multiple than the use of fist or legs.

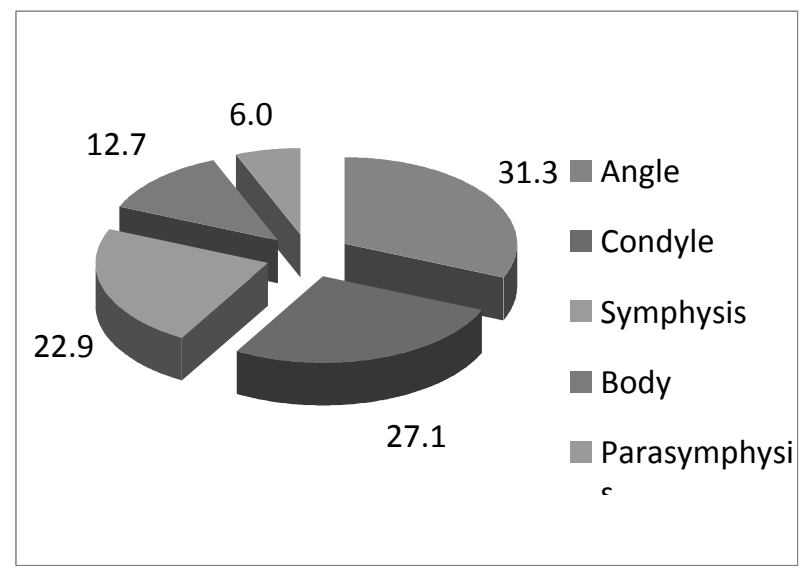

Figure 1 Fracture distribution by site

Figure 1 shows the distribution of fractures by site. No fracture occurred in the coronoid process, but the majority occurred at the angle and condyles. Of the 128 
fractures sustained at the angle, condyles, body and parasymphysis, 83 were on the left side of the mandible while 45 were on the right.

All the patients were treated by closed reduction technique but the 11 patients that had displaced angle fractures also had transosseous wiring. The fractures healed successfully within four to six weeks period except those that were complicated which required further varying periods of treatment to effect union. The complications recorded were delayed union $5(38.4 \%)$, infection $3(23.1 \%)$, paraesthesia/anaesthesia of the lower lip 3(23.1\%) and malunion 2 (15.4\%).

\section{DISCUSSION}

The most common aetiological factor causing a breach in the continuity of the mandible is trauma. ${ }^{1-4}$ From the available literature ${ }^{6-12}$ in both developing and developed countries, the frequency of a particular type of trauma as an aetiological factor is influenced by the socio-economic and lifestyles of the community under consideration. Domestic violence is a source of considerable morbidity and because of the distress associated with it and its effect on the family asking directly about violence as a cause or contributory factor to a patient's injuries may save time, money and the patient.

In the present study injuries were inflicted by either blunt or penetrating forces or a combination of both. The fist was a favourite means of assault in $56.2 \%$ of the patients. Weapons were used in $37.0 \%$. These weapons include blunt and sharp objects like sticks, pipes and matchet.

The pattern of mandibular fracture with respect to the site and type recorded was similar to that in other studies on assault victims. ${ }^{6,8,9}$ This is due to the preference and accessibility of the face as a target for assailants. The left side of the mandible was fractured more than the right. This reflects the fact that the most common mechanism of injury was the fist and that more than $90 \%$ of the population is right handed. ${ }^{10}$

Grinker and Saks ${ }^{11}$ suggest that hemispherical cerebral dominance leads the victim to turn to the right in a reflexive manner to avoid being punched, thus presenting the left side of the face to the assailant. As earlier reported by authors ${ }^{2,6}$ who carried out studies on the aetiology of mandibular fractures when altercation is considered, the angle and condyles were the most common sites affected.

These anatomic sites have been reported ${ }^{13}$ to significantly influence the development of complications especially if treatment is delayed and because of the management protocol. In addition, the mandibular angle region has a relatively small cross section and the oblique and irregular fracture configuration make treatment outcome unfavourable. ${ }^{14}$

Hence the need for early institution of appropriate treatment by the oral and maxillofacial surgeon and also prompt referral of these patients by other physicians involved in the management. Also no fracture occurred in the coronoid process because of its anatomical location and temporalis muscle attachment that gives it protection.

The average number of mandibular fractures per patient was 2.3. This is higher than the 1.21 obtained by Le et $a^{3}$ but similar to the studies of authors ${ }^{8,12}$ reporting on multiple aetiologies. The high rate of number of fractures may reflect the brutal force used by the assailant on their victims.

The age and gender disposition of patients is the same as that of the studies by earlier authors. 6,12 The preponderance of males could be attributable to habits, occupation and their natural aggressive tendencies. The marital status of the patient appears not to be a significant contributory factor. A search in the literature did not yield any study linking marital status to domestic violence.

The social class of patients in the present study is similar to that of Adi et al ${ }^{6}$ but differs from those of Roode et al ${ }^{12}$ who identified no difference in social class. The harsh challenges of economic life in Nigeria may have contributed to the involvement of more patients in the middle and lower social class with domestic violence. There was significant association between social class and type of fracture sustained. Patients in the lower social class were more likely to sustain multiple fractures.

\section{CONCLUSION}

Mandibular fractures due to domestic violence do occur and constitute part of the cases encountered by the practising oral and maxillofacial surgeon. Although family and emergency physicians are sometimes considered to see patients with domestic violence, the oral and maxillofacial surgeon should braze up to the challenges of being involved in the care of these patients and be cognizant to the surgical and social implication of this type of injury.

\section{REFERENCES}

1. Moshy J, Mosha HJ, Lema PA. Prevalence of maxillo-mandibular fractures in mainland Tanzania. East Afr Med J 1996; 172-175. 
2. Bataineh AB. Aetiology and incidence of maxillofacial fractures in North of Jordan. Oral Surg Oral Med Oral Radiol Endod 1998; 86:31-35.

3. Le BT, Dierks EJ, Ueeck BA, Homer LD, Potter BF. Maxillofacial injuries associated with domestic violence. J Oral Maxillofac Surg 2001; 59: 1277-1283.

4. Grisso JA, Wishner AR, Schwartz DF, et al. A population-based study of injuries in inner-city women. Am J Epidemiol 1991; 59: 134-138.

5. Adedeji GA. Socio-economic and cultural background of hospitalized children in Ilesha, Nigeria. Nig J Paed 1985; 12: 111-117.

6. Adi M, Ogden GR, Chisholm DM. An analysis of mandibular fractures in Dundee, Scotland (19771985). Br J Oral Maxillofac Surg 1990; 28: 194199.

7. Akama MK, Chindia ML, Ndungu FL. Occurrence and pattern of mandibular fractures in Kisii District Hospital, Kenya. East Afr Med J 1993; 70: $732-733$
8. Asadi SG, Asadi Z. The aetiology of mandibular fractures at an urban centre. $J$ RSoc Health 1997; 117: 164-167.

9. Anderson L, Hultin M, Nordenram A. Jaw fractures in the county of Stockholm. Int J Oral Surg 1984; 13: 194-197.

10. Dejong NR. The neurological examination. 2nd ed. New York: Pitman Medical Publishing Company 1958.

11. Grinker RR, Saks AL. The cerebrum-cerebral hemispheres, in Neurology 6th ed. Springfield 11: Charles C. Thomas, 1984, p. 142.

12. Roode GJ, Van Wyke PJ, Botha SJ. Mandibular fractures: an epidemiological survey at the Oral and Dental Hospital, Pretoria. SADJ 2007; 62: 272-274.

13. Haug RH, Schwimmer A. Fibrous union of the mandible. A review of 27 patients $J$ Oral Maxillofac Surg; 52:832-835.

14. Zachariades N, Papademetriou I. Complications of treatment of mandibular fractures with compression plates. Oral Surg Oral Med Oral Pathol Radiol Endod; 79: 150-153. 